\title{
Social Mapping for Supporting Sensemaking and Collaboration: the Case of Development Informatics Research in South Africa
}

\author{
Mario MARAIS ${ }^{1}$ and Judy VAN BILJON ${ }^{2}$ \\ ${ }^{1}$ CSIR, Meiring Naude Road, Pretoria, 0081, South Africa \\ Tel: +27 12 8413771,Fax: + 2712 8414720,Email:mmarais@csir.co.za \\ ${ }^{2}$ University of South Africa, Corner Christiaan de Wet \& Pioneer Avenue, \\ Florida, Johannesburg, 1709, South Africa \\ Tel: +27116709182,Email: vbiljia@unisa.ac.za
}

\begin{abstract}
Development Informatics is a multi-, inter- and transdisciplinary field encompassing various research philosophies, realities and priorities. This diversity complicates connection and collaboration between researchers in the field and that can undermine the growth and impact of Development Informatics research. The objective of this paper is to propose social mapping as a mechanism to support research collaboration through communal sensemaking. Social mapping technology is used to represent the South African Development Informatics research landscape towards identifying behavioural collaboration patterns. The data set includes the associations, collaborations and publication choices of at least 50 South African researchers. Despite the limitations in terms of scope the results demonstrate that social mapping has the potential for presenting research connections visually in a way that supports the sensemaking of the social dynamics within the society. Besides the visual representation of researcher connections to conferences and research areas the research also provides insights into the data capturing challenges for social mapping. The findings provide a point of departure towards understanding the research collaboration patterns and publications patterns that may impact Development Informatics research.
\end{abstract}

Keywords: Development Informatics, ICT4D, social mapping, participatory community mapping, socio-technical systems

\section{Introduction}

Using Information and Communication Technology (ICT) to connect people in support of collaboration is not new to Africa. Examples include the Mankosi community network [1] and the Africa Build project [2]. Considering African and South African Development Informatics Research Communities there are ICT collections focused on Sub-Saharan Africa but most are silos of excellence that still need to be connected to the social research network [3]. Participatory Community Mapping has proven potential for connecting communities in a sustainable way [4]. Participatory Community mapping as a sociotechnical innovation integrates the social institution of communities with the newest frontiers of material society through the joining and convergence of community with information sciences and technologies [5]. Research communities co-exist in a complex context of relations and interactions with other communities, supported by a multi-layered technical infrastructure. To improve their collaboration, community members and network stakeholders need to continually make sense of this context [4]. The Development Informatics (DI) community experience challenges in collaboration due to the multi- and transdisciplinary nature which necessitates sharing knowledge from dissimilar disciplines 
[6]. The diversity in the stakeholders, which include researchers, funding agencies, government departments, participants and practitioners from the developing, emerging and developed economies introduce further complexities in knowledge management and knowledge sharing [7].

This knowledge management complexity underlie the challenge of building on existing knowledge towards research standards, methodologies and theories as advocated by Burrell and Toyama [8] and Walsham [9], agreement on how research quality can be ensured [10][11] and collaboration between diverse stakeholders towards community building [12]. According to De Moore [13] community-building is an iterative process in which community members increasingly become aware of what binds them, and the increased level of awareness can inform, shape and trigger new community building activities. According to Rey-Moreno, Miliza, Mweetwa, van Stam, \& Johnson [14] the main opportunities of wireless Community Networks are the engagement of community members and the provisioning of a space for their development, in the community, for the community.

In the multi-, inter- and transdisciplinary research areas such as DI research, there are researchers from related fields as well as stakeholders that are interested in getting a quick overview of the research landscape of the DI community. The need involves basic knowledge in response to questions such as: who are the DI researchers, which institutions are they affiliated with and what are their fields of specialisation? How do DI researchers disseminate their research (considering conferences and journals) and who do they collaborate with? This knowledge is not available to novice researchers or international researchers without access to a South African DI champion. An open knowledge repository has been proposed to provide this knowledge [15][16] in an accessible format and support sensemaking.

Formalization of sensemaking efforts help to reduce ambiguity and to create common foundations for collaborative action [17]. A core communal sensemaking activity is community mapping. Originally started as a cartographic exercise to map the geographical connections and common ground that local communities share, community mapping is also being used for providing visualizations of argumentation and conversations [18]. Communal sensemaking can aid development. An example is the use of communication and mapping technology to connect individuals in geographical communities that live in the same area, but live separate lives and have individual experiences of the various and often uncoordinated development interventions. In the DI field it can break down the boundaries between the disciplines of researchers (e.g. computer science, geography, development studies, community development) and the boundaries between researchers and implementing bodies such as non-governmental organizations (NGOs) to create a communal space for sensemaking. The effectiveness of the implementation of development can be improved via communal sensemaking that is inclusive, e.g. both top-down and bottom-up development perspectives are engaged with each other, and collaborative, since interactions between the diversity of development actors and experts surface the necessity for coordination. In SA this is a major need of the Department of Rural Development and Land Reform [19] as evidenced at the five week strategy session in Sept/Oct 2016 that was attended by one of the researchers. The possible beneficiaries of the creation of a communal space for sensemaking include different stakeholders in development: researchers, funding agencies, government departments, development beneficiaries (participants) and practitioners.

The South African Development Informatics researchers' affiliations and conference publications have been reported in related research [20]. This study revisits the conference publications patterns and extends the previous work by including the research domains. The objectives of this research programme is to improve development in SA by improving the 
collaboration among the stakeholders mentioned above by providing a platform for knowledge sharing across the multi-, inter- and transdisciplinary research areas related to DI research and implementing communal sensemaking processes among the diversity of stakeholders in development. In short, the plan is the development of a community of researchers that make sense of development informatics and then the use of the experience gained in this process to develop a large community of development stakeholders.

The purpose of this paper is to explore the use of social mapping in support of collaboration by considering the case of South African Development Informatics research community. Geographical community mapping methods stress strong community participation in the map making process. Therefore we document the social mapping process and engage the community for consent, peer-review and feed-back. We outline the approach being developed; present initial results of applying social mapping in the case of the South African DI community, and reflect on the lessons learned in this exploration of community mapping.

\section{Knowledge Management for Participatory Community Mapping}

The literature review covers knowledge management, the design of knowledge repositories in ICT for Development (ICT4D) and the use of social mapping in supporting knowledge management.

\subsection{Knowledge Management and ICT4D Knowledge repositories}

The objective of a Knowledge Management System (KMS) is to support the construction, sharing and application of knowledge in organizations [21]. This means that the KM activities consists of the administration of knowledge assets of an organization and the sharing and enlargement of those assets [22]. The terms knowledge transfer and knowledge sharing have not been well-distinguished. According to Paulin and Suneson [23] authors who use the term knowledge transfer tend towards the objectivist perspective of knowledge while knowledge sharing is used with a more subjective perspective i.e. sharing via synchronous or asynchronous conversations and communications between people. Knowledge exchange towards sharing ideas and resources is crucial for the development of any research field. As noted, DI inhabits an interdisciplinary space which complicates knowledge management and the accessibility of research related knowledge [11]. Extant literature has shown that the effectiveness of IT artefacts can be demonstrated through knowledge sharing activities [24]; conversely these activities can generate valuable insight in improving knowledge sharing towards supporting communication and ensuring a solid foundation for collaboration. Knowledge management systems used in the ICT4D context are known by different names including e-portals, online knowledge repositories and knowledge sharing platforms (KSPs). All of these systems are essentially Web based collections of information providing varying degrees of access and interaction but there are critical differences between what knowledge is made available, the target audience, the access and the interactions [25]. KM is recommended as part of any DI project to optimize its probability of success specifically by sustaining and growing a user community of practice $[7 ; 26]$. The provision of a social map also makes a practical contribution to development by creating an awareness of the social infrastructure that accompanies the technological infrastructure and the need to adopt a socio-technical systems (STS) view [27]. In this research the social mapping is part of a bigger goal, namely to create an open knowledge repository which supports identification of relevant research and possible collaborations, discussions and the formation of communities of practice to share information such as: research agendas, funding opportunities, publication opportunities, methodologies, theories, models and frameworks with the wider DI community including practitioners, government and NGO's. 
KM requirements need to continually adapt to fit the needs of the intervention. In the context of ICT4D the nature of the intervention has changed over time; Heeks [28] refers to phase ICT4D 0.0 (use of computers in the economy), 1.0 (ICT as development tool telecentres) and 2.0 (ICT as the transformative platform for development). Participation to foster innovation is key, and Heeks (ibid.) refers to innovation strategies as being pro-poor (for the poor), para-poor (working with the poor) and per-poor (innovation by the poor in their communities).

In an ICT4D 1.0 approach, KM can be applied to sustain technology support and maintenance without the aid of the original development team [7] or remote experts [29]. An example of ICT4D 2.0 para-poor innovation is the development of a pharmacy system for antiretroviral drug dispensing in South African public health clinics [30]. The research and development team adopted the concept of Open Development [31] which emphasizes universal access to information, collaborative participation in knowledge creation and diversity of knowledge systems. In this approach Louden and Rivett [30] contend that communities of practice may be the route to "actionable knowledge" [32] that is developed and sustained after the end of research processes and projects. In the broad DI context there are multiple stakeholder communities including beneficiaries, practitioners, academia, government, civil society (e.g. NGOs) and private sector organisations. The diversity of the target audience for a knowledge management endeavour is challenging if an open access environment is planned. For example, academics may seek examiners, reviewers and collaborators, while funding agencies and NGOs may seek research experts in a specific field. Students and novice researchers may seek links to reputable sites and research opportunities. Considering educational use the number of social networking technologies has led to complex choices and challenges when it comes to exploiting the advantages these technologies [33]. The community context influences the nature of the formal and informal knowledge production processes and the tools that need to be supported. Wenger, White and Smith [34] advocate for the use a range of tools and platforms to support communities of practice. Wenger et al (ibid.) mapped the activities of communities of practice by using two dimensions: formal versus informal sharing and information flows from external sources versus sharing with external sources. In this map participatory community social mapping can be described as informal rather than formal sharing which leads to "Building shared understanding" and also provides a means of "Producing assets" that may be shared within the community and with external sources.

Participatory community social mapping needs a visible, reliable and stable basis to operate on. Based on a survey among Development Informatics researchers in South Africa (SA), Platz and van Biljon [3] found support for an browser-based ICT4D knowledge repository that could typically host the information required for community mapping. Prioritising the functionality to be included in a knowledge repository is not trivial. To optimize and facilitate the development process, an ICT4D knowledge repository maturity matrix has been developed that delineates the desired characteristics according to the maturity levels [16].

\section{Research Design}

The community was defined as Development Informatics or ICT4D researchers in SA. The researchers were identified by doing a Google Scholar search using the terms "Development Informatics" or "ICT4D" and "South Africa'. The search was carried out during September 2016. The result produced both South African and non-South African researchers so the list was checked against attendance lists of researchers who attended ICT4D events organised at the 2014 and 2015 annual Conferences of the South African Institute of Computer Scientists and Information Technologists (SAICSIT). The search returned 66 names and those were contacted for consent to use their information. 
Consequently 52 replied: 51 positively and one declined. These researchers are a subset of the local ICT4D researchers since multi-, inter- and transdisciplinary nature of this field means that researchers may attend a wide range of specialist conferences, e.g. development studies, engineering or information science conferences.

The following information categories were then added to a spreadsheet for the researchers who consented: their affiliations (institution where they were employed), the conference proceedings published in, the journals published in and the domains or subfield(s) of DI or related fields that they were involved in. The researcher affiliations would indicate which institutions had a sizable research effort and which researchers were fairly isolated. Co-affiliations would also show structured collaboration. The information on the publications and the domains of research was collected in order to determine if clusters of research interest existed in this community. A total of 16 institutions were added which include universities and other research institutions such as the Council for Industrial and Scientific Research (CSIR). The researchers had published in 24 conference proceedings and in 38 journals. The data set on researchers' affiliations and publications is not static as new publications need to be added as they become available and researchers may also change their affiliations. It is almost impossible to have a complete and accurate dataset at any given time but the purpose of the mapping is to provide an overview of the landscape and how it has changed (for example by including previous affiliations) rather than to provide a snapshot in time. This also demonstrates the need for regular updating of the map by the community members.

\subsection{The Mapping Language}

The mapping language needs to distinguish between elements (depicting socio-technical concepts of the community network) and connections (representing relations and interactions between those elements). Informed by the participatory community mapping knowledge structure proposed by De Moor [13] the following structure was constructed.

\subsubsection{Elements}

We distinguish the following elements:

- Participants including Persons; Institutions; Conferences; Journals and Domains

- Activities (Activities are outcomes as well, but being processes, they can also generate other processes and results and are a direct source of community building).

- Events such as conferences and workshops

○ Funding proposals

- Calls for papers relating to conferences and journals

- Results (tangible static results like publications)

- Tools that can be used to support activities.

○ Physical Meetings (e.g. "Annual Meetings", "Network Meetings", "Presentations", "Conferences").

○ Online Tools (e.g. participant websites and social media such as project apps, Twitter, Facebook and WhatsApp).

\subsubsection{Connections}

Communities are networks of relationships and interactions for mutual benefit. A conceptual model of community can be described as consisting of collective identity, local participation, and diverse support networks [13]. Carrol [35] mentions four composite variables for community membership and participation, namely: Belonging (identity), Informedness (passive participation), Activism (active participation), and Associations (support networks). De Moor [15] built on this approach to identify four types of connections, ordered in increasing degree of participant involvement: 
- Informedness (being informed about activities of the community, but not being part of it).

- Associations (being an explicit member of the community in the sense of having made a commitment to participate)

- Participation (actual participation in the activities of the community)

- Producing (producing visible, measurable results as outcomes of the activities. This is the most involved kind of participation).

Given our approach to data capturing (as explained before) all the researchers had published papers. However, it would be possible to extend the data set to include researchers who have not published and to also make distinctions to reflect the level of participation according to specified criteria. There could be a tension between being complete and being useful. For example, adding postgraduate students who have published may give a more complete picture but for a person looking for an examiner for doctoral students adding students would diminish the usefulness if they cannot be distinguished.

The map making has been done by the authors with the help of three research assistants to capture and validate the data. Ideally, community managers or members should be involved and be trained to become map makers but given the complexity of the mapping language, tool, and process that may not be feasible, also in terms of the time and effort required. De Moor [13] also distinguished various levels of map making literacy including the overall structure, layout, and functionality of a community map which could be created by a "master map maker". Selected community managers or members could be trained to expand the partial "domain maps". They could focus on adding "more of the same" participants and activities, for instance, and filling out the data fields of the various elements and connections. The map of a dynamically evolving community is never complete and there is always a trade-off between completeness and feasibility. For researchers as community members, the main reasons to contribute to and use the map are to see the bigger picture as correct and complete and to ensure that their participation as researchers is fully represented.

In summary, the researchers were abstracted as the object type person, together with institution, conference; journal and research domain as object types. The connections affiliation (between person and institution) and publish (between person and conference and also between journal and conference) as well as domain between (research domain and person) were then added to the connections table. The findings are limited by the incomplete nature of any map of a dynamic community. The publication data was captured from the Internet using Google Scholar; using another search engine may provide different more information. The next step will be to present the map to the researchers to give feedback on the map towards updating their information and then this will be shared with the wider DI community.

\section{Results}

Figures 1 and 2 are examples of how the information about the community can be depicted to support sensemaking of the connections. Figure 1 depicts the most popular conferences (attended by more than two researchers) while Figure 2 depicts the researchers' domains.

The researchers included have all consented to their data being used but given time constraints they have not all been able to confirm the correctness and completeness of the data. There is little concern about the correctness of the data (as abstracted from online publication databases) but the completeness cannot be guaranteed. In related research, sense making theory has been used to explain the making and inevitable unmaking of sense [20]. Communal sensemaking data is dynamic and the changes across time and space mean that data can only be verified as correct and complete up to a set date. The goal was to have it 
verified up to December 2016. Given the challenges to identifying and capturing all the researchers data it is has to be acknowledged that the data is not complete.

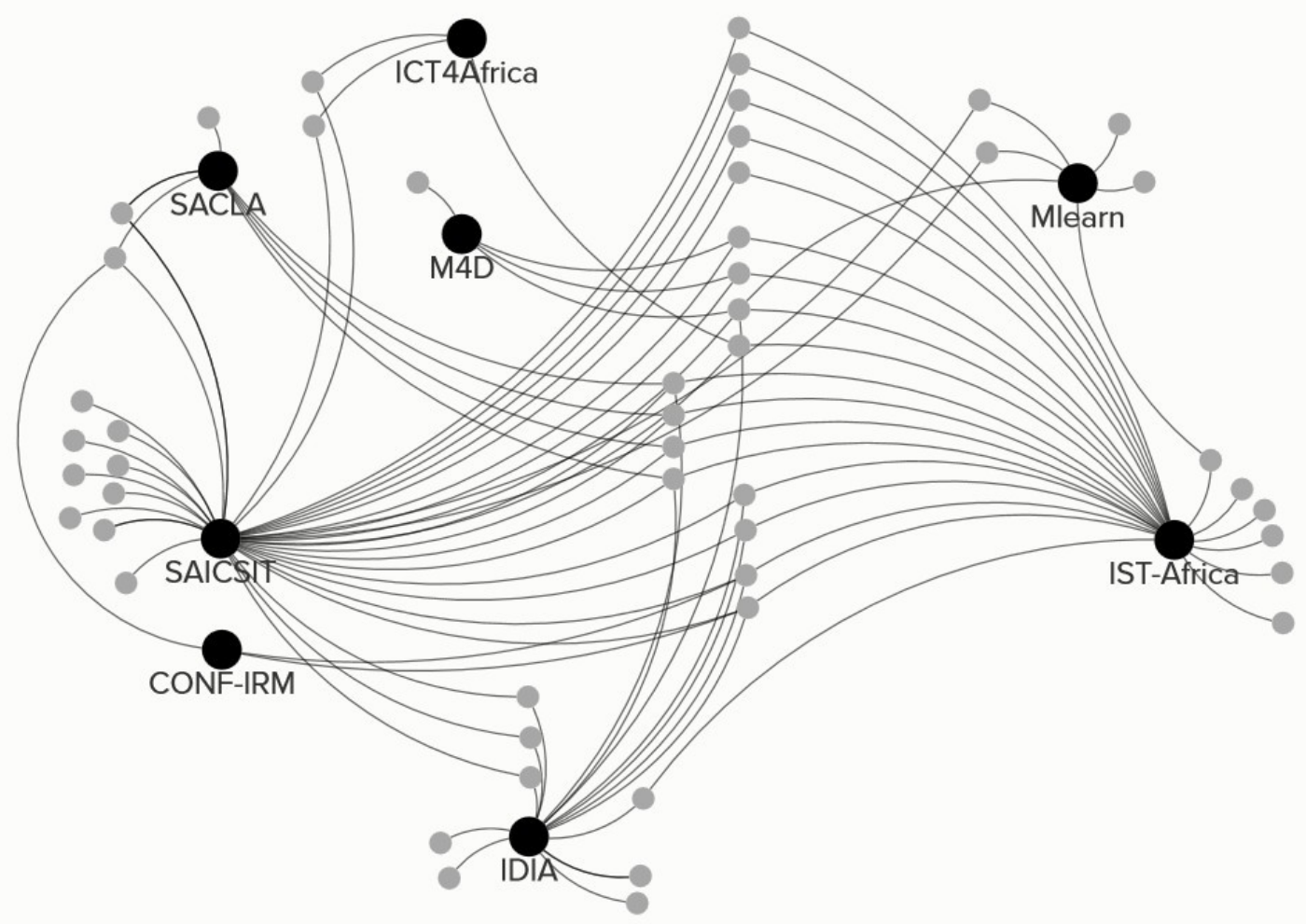

Figure 1: Popular conferences among the sampled researchers

The South African Institute of Computer Scientists and Information Technologists SAICSIT (62), IST-Africa (31) and International Development Informatics Association (IDIA) (21) conferences had the most attendees and many attendees attended two or all three of these conferences as illustrated by the five vertical and linear groupings of researchers in the central section of Figure 1. The SAICSIT conference is a general South African based Computer Science and Information Systems conference which means that these publications were not necessarily in the domain of Development Informatics. ISTAfrica and IDIA are important international Development Informatics conferences. The fact that at least 17 researchers attended both SAICSIT and IST-Africa, and three attended SAICSIT and IDIA, indicates a significant development interest among the SAICSIT attendees. More than half of the IST-Africa attendees also attended SAICSIT. IDIA (organised by Monash University South Africa) is hosted mostly in the Global South and therefore provides important networking and collaboration opportunities in Africa. The importance of research regarding mobile device use is reflected in the attendance of the Mobile Communication Technologies for Development (M4D) and the Mobile and Contextual Learning (Mlearn) conferences, which also provides some indication of the size of this particular research community.

It was surprising that the ICTD and International Federation for Information Processing (IFIP) Working Group 9.4 (Social Implications of Computers in Developing Countries) conferences were not included. Upon investigating it was found that some of the researchers have actually published there but it was not reflected in the data they provided. The highlights the need for a qualitative, top-down investigation to uncover information that was not retrieved either because it was not available online or due to the data capturing process. This overview of the conferences and the attendance frequency could be valuable to inform novice researchers and international researchers interested in publishing and 
networking towards collaboration with South African Development Informatics researchers.

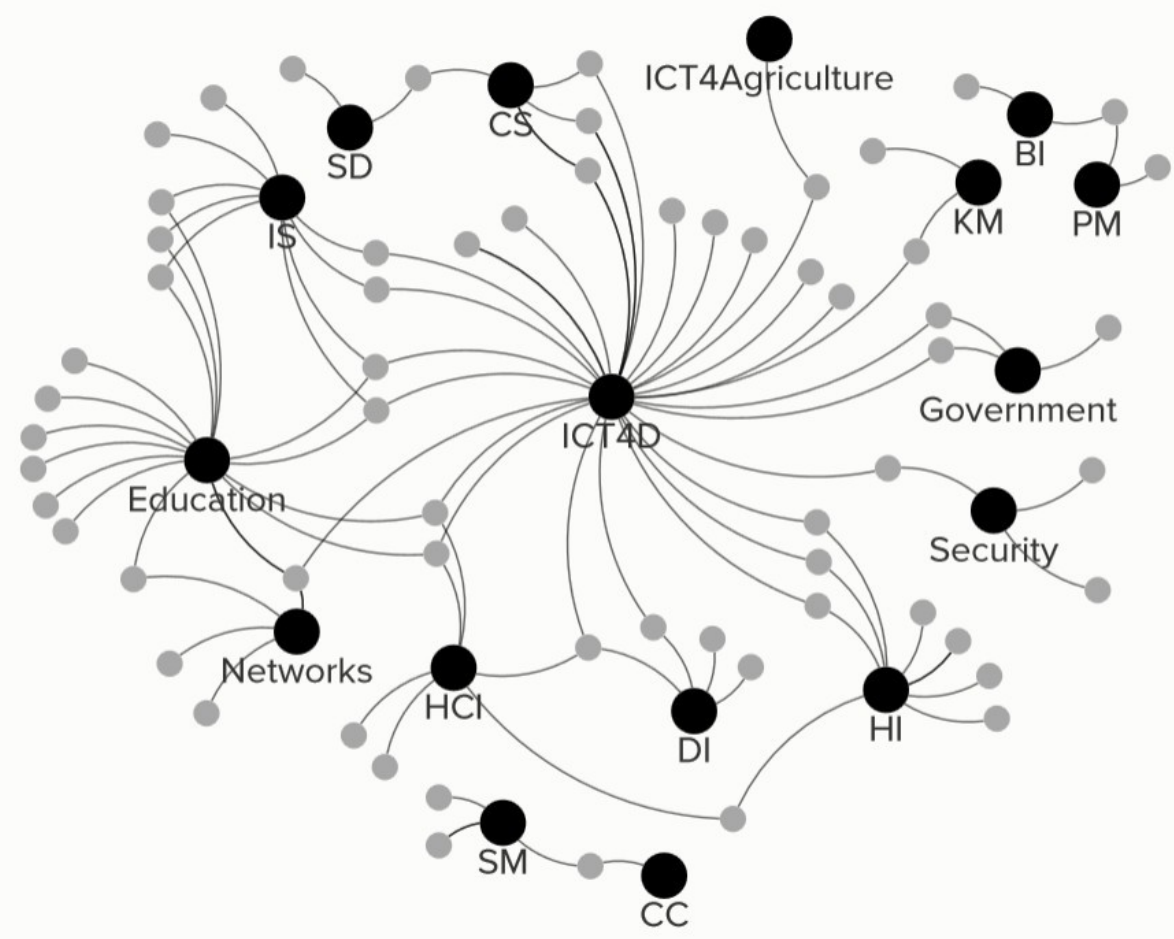

Figure 2: Clustering around research domains

Figure 2 shows the connection between researchers and research domains which is an important map for determining the active research fields and the researchers working in these fields. ICT4D has the most connections (30 researchers) followed by Education (15). However, given the fact that ICT4D and DI are sometimes used interchangeably, for example two of the researchers combined ICT4D and DI, the ICT4D and DI connections could be combined. Researchers were also asked to place themselves in a discipline and that is depicted as the connections to Information Systems (IS, 9), Computer Science (CS, 4), and/or Human-Computer Interaction (HCI, 6). IS researchers were mostly active in the domain of Education and/or ICT4D. Only two researchers mentioned only ICT4D or DI, indicating that most researchers identified with other disciplines as well.

The domain of Health Information (HI) was well represented (8). The following domains and sub-domains were mentioned but with less connections: Government, Agriculture, Security, Project Management (PM), Networks; Business Intelligence (BI), Big Data, Cloud Computing (CC); Software Development (SD); Knowledge Management $(\mathrm{KM})$, and Social Media (SM). The naming of the domains were based a selection of literature based domains [36] but some domains were added according to participants inputs. Agriculture is an important source of jobs in South Africa and ICT research is expected to be more prominent [19]. This shows the general need to investigate domain specific conferences and publications to identify additional research in ICT for Development.

\section{Conclusions}

This paper outlined the use of participatory, community mapping in a project piloted for South African DI researchers. The initial findings show potential for mapping the Development Informatics community towards representing an easy to understand overview of the current focus of publications and research activity in specific domains. The moral 
challenge for community mapping is to ensure that the selection is as accurate and unbiased as possible so that all community members can participate in and benefit from the innovation. A qualitative, top-down investigation that covers the domains relevant to the development strategy of SA is required to identify research that uses ICT as an enabler, but is not necessarily identified as ICT4D or DI. A communication strategy will be developed to make this research known to the researchers in the non-IS and non-CS departments at the research institutions of SA. Research is required to extend and refine the mapping process and to widen the focus to ethical issues and the dynamics of benefit to the community. The social mapping component will be integrated into the South African Development Informatics \& ICT4D Platform (SADIIP) currently under construction which will increase the usefulness for a wider community interested in development and informatics.

\section{Acknowledgement}

This work is based on the research supported by the South African Research Chairs Initiative of the Department of Science and Technology and National Research Foundation of South Africa (Grant No 98564). We acknowledge all the South African researchers who allowed us to use their data as part of this research.

\section{References}

[1] C. Rey-Moreno, A. G. Sabiescu, M. J. Siya, and W. D. Tucker, "Local Ownership, Exercise of Ownership and Moving from Passive to Active Entitlement: A practice-led inquiry on a rural community network," J. Community Informatics; Vol 11, No 2 Spec. Issue Communities Technol. Curr. Res. Think., vol. 11, no. 2, pp. 1-16, 2015.

[2] M. Ramirez-Robles, A. Jimenez-Castellanos, A. Khalifa, A. Anne, Y. N. Kamga, S. Afagbedzi, and V. Maojo, "AFRICA BUILD portal: Developing a social network of African health researchers and educators," in IST-Africa Conference and Exhibition (IST-Africa), 2013, 2013, pp. 1-8.

[3] M. Platz and J. Van Biljon, "Design of an open ICT4D knowledge repository," in 2015 IST-Africa Conference, IST-Africa 2015, 2015, pp. 1-11.

[4] A. De Moor, "Communities in context: Towards taking control of their tools in common(s)," $J$ Community Informatics, vol. 11, no. 2, pp. 4-9, 2015.

[5] J. M. Carroll, P. C. Shih, and J. Kropczynski, "Community Informatics as Innovation in Sociotechnical Infrastructures," J. Community Informatics, vol. 11, no. 2, 2015.

[6] G. Walsham, "Development Informatics in a Changing World : Reflections from ICTD2010/2012," Inf. Technol. Int. Dev., vol. 9, no. 1, pp. 49-54, 2013.

[7] S. Conger, "Knowledge Management for Information and Communications Technologies for Development Programs in South Africa," Inf. Technol. Dev., vol. 1102, no. ahead-of-print, pp. 1-22, 2014.

[8] J. Burrell and K. Toyama, "What Constitutes Good ICTD Research?," Inf. Technol. Int. Dev., vol. 5, no. 3, pp. 82-94, 2009.

[9] G. Walsham, "Are we making a better world with ICTs? Reflections on a future agenda for the IS field," J. Inf. Technol., vol. 27, no. 2, pp. 87-93, 2012.

[10]R. Weber, "Research on ICT for Development : Some Reflections," no. October, pp. 2-27, 2009.

[11]W. J. Tibben, "Theory Building for ICT4D: Systemizing Case Study Research Using Theory Triangulation," Inf. Technol. Dev., vol. 21, no. 4, pp. 628-652, 2015.

[12]N. Jabagi, J. Jiang, D. MacLean, S. Chalmeau, and J. Yang, "Communicating to Practitioners through IS Research : a Descriptive Review," in Twenty-second Americas Conference on Information Systems, San Diego, California, 2016, no. 1999, pp. 1-10.

[13]A. De Moor, "Towards a participatory community mapping method: the Tilburg urban farming community case," Adjun. Proc. Communities Technol. Conf., vol. 12, p. 11, 2015.

[14] C. Rey-Moreno, J. Miliza, F. Mweetwa, G. van Stam, and D. L. Johnson, "Community Networks in the African Context: Opportunities and barriers," AfriCHI, pp. 237-241, 2016.

[15]M. Platz and J. Van Biljon, "Design of an open ICT4D knowledge repository," in IST-Africa 2015 Conference Proceedings, Paul Cunningham and Miriam Cunningham (Eds), IIMC International Information, Management Corporation, 2015, pp. 1-11.

[16] M. Platz and J. Van Biljon, "Development of a First Version of a Maturity Matrix for ICT4D Knowledge Repositories," Conf. Proc., pp. 978-1, 2016.

[17]P. W. L. Vlaar, F. A. J. Van den Bosch, and H. W. Volberda, "Coping with Problems of Understanding in 
Interorganizational Relationships: Using Formalization as a Means to Make Sense,” Organ. Stud., vol. 27, no. 11, pp. 1617-1638, 2006.

[18]A. Okada, S. Buckingham, and T. Sherborne, Knowledge Cartography: Software tools and mapping techniques. London, UK: Springer, 2008.

[19]M. A. Marais, "Researcher notes. Phakisa workshop of the Department of Agriculture, Forestry and Fisheries with the Department of Rural Development and Land Reform," Kemptonpark, Johannesburg, 2016.

[20]J. van Biljon and M. Marais, "Social Mapping for Communal Sensemaking: the case of Development Informatics Researchers in South Africa," in The 14th International Conference on Social Implications of Computers in Developing Countries. IFIP WG 9.4, 2017.

[21]D. Leidner, "Knowledge management and knowledge management systems," J. Strateg. Inf. Syst., vol. 9 , no. $2-3$, pp. 101-105, 2000.

[22]M. Ben Chouikha and S. Dakhli, "The Dimensions of Knowledge Sharing," MCIS 2012 Proceedings. Pap., p. 16, 2012.

[23]D. Paulin and K. Suneson, "Knowledge Transfer , Knowledge Sharing and Knowledge Barriers - Three Blurry Terms in KM,” Electron. J. Knowl. Manag., vol. 10, no. 1, pp. 81-91, 2012.

[24] T. Li, "The Interplay between Knowledge Sharing and IT Artifacts in the Working Contexts," in Twentysecond Americas Conference on Information Systems, San Diego, 2016, pp. 1-10.

[25] G. Mosweunyane and L. A. Carr, "Direct desktop-repository deposits with SWORD," in 2014 IST-Africa Conference Proceedings, 2014, pp. 1-8.

[26]J. P. Singh and M. Flyverbom, "Representing participation in ICT4D projects," Telecomm. Policy, vol. 40, no. 7, pp. 692-703, 2016.

[27]B. Whitworth and A. De Moor, Handbook of Research on Socio-Technical Design and Social Networking Systems. New York: IGI Global, 2009.

[28]R. Heeks, "ICT4D 2.0: The next phase of applying ICT for international development," Computer (Long. Beach. Calif)., vol. 41, no. 6, pp. 26-31, 2008.

[29] M. Geldof, D. J. Grimshaw, D. Kleine, and T. Unwin, "What are the key lessons of ICT4D partnerships for poverty reduction?," 2011.

[30] M. Loudon and U. Rivett, "Enacting Openness in ICT4D Research,” Inf. Technol. Int. Dev., vol. 7, no. 1, pp. 33-46, 2011.

[31] M. L. Smith and L. Elder, "Open ICT ecosystems transforming the developing world," Inf. Technol. Int. Dev., vol. 6, no. 1, pp. 65-71, 2010.

[32] G. Hearn and M. Foth, "Action research in the design of new media and ICT systems," in Topical issues in communications and media research. New York: Nova Science, 2005, pp. 79-94.

[33]J. Murumba, E. Micheni, and A. Njuguna, "Evaluating preparedness for social networks integration into learning: A case study of Inoorero University," in 2015 IST-Africa Conference, IST-Africa 2015, 2015, pp. 1-11.

[34]J. D. Wenger, E., White, N., Smith, Digital Habitats: Stewarding technology for communities. Portland: CPsquare, 2009.

[35] J. M. Carroll, The Neighborhood in the Internet: Design Research Projects in Community Informatics, New York: 1st ed., Routledge, 2012.

[36]J. VanBiljon and T. Alexander, "Chapter 5: A Conceptual Framework for ICT4D," in ICTs for Inclusive Communities in Developing Societies, J. Steyn and D. van Greunen, Eds. Cambridge Scholars Publishing, 2015, pp. 84-106. 